\title{
O DESAFIO DO MINISTÉRIO PÚBLICO COMO AGENTE DE TRANSFORMAÇÃO: RESPONSABILIDADE POLÍTICA E SOCIAL
}

\author{
The challenge of Public Attorney as processing agent: \\ political and social responsibility
}

\author{
Andréia Ribeiro Rodrigues Barboza ${ }^{1}$ \\ Tiago do Amaral Barboza ${ }^{2}$
}

\section{Resumo}

No presente trabalho expõe-se breve perfil pós-constitucionalista do Ministério Público do Estado de São Paulo e sua missão de acompanhar a efetivação das políticas públicas para transmudação de garantias meramente formais em materiais - notadamente concretização de direitos sociais. Para tanto, a complexidade das problemáticas sociais de uma nação em desenvolvimento e a multidisciplinariedade de conhecimentos exigidos evidenciam a imprescindibilidade do assessoramento técnico por profissionais da área de Serviço Social. A partir disso, assistentes sociais ingressaram em 2005 no MP/SP e criaram junto com membros do Ministério Público o Núcleo de Assessoria Técnica Psicossocial (NAT), com atribuições voltadas para avaliação de políticas públicas e na defesa de interesses coletivos. Neste artigo é discutida a atuação do NAT à luz do trabalho do assistente social no assessoramento aos promotores de justiça, disso derivando resultados positivos na missão de alterar-se a realidade social.

Palavras-chave: Ministério Público. Serviço Social. Políticas Públicas. Direitos Sociais. Transformação Social.

\begin{abstract}
In the present work, is a brief post- constitutionalist profile of the Public Attorney of the State of São Paulo and its mission to monitor the effectiveness of public policies for transmutation of purely formal guarantees on materials - notably realization of social rights. Therefore, the complexity of the social problems of a developing nation and the multidisciplinary nature of knowledge required highlight the indispensability of technical advice by professionals in the field of Social Work. From this, social workers joined in 2005 in the MP / SP and created with prosecutors the Technical Assistance Center Psychosocial (NAT), with assignments aimed at evaluation of public policies and in defense of collective interests. In this article, we discuss the NAT's performance in the light of the social worker work in advising the prosecutors, that deriving positive results in the mission to change the social reality.
\end{abstract}

Keywords: Public Attorney. Social Work .Public Policies. Social Rights. Social Transformation.

\footnotetext{
${ }^{1}$ Pós-graduada em Serviço Social, Saúde e Violência pelo Programa de Aprimoramento Profissional da Faculdade de Ciências Médicas, UNICAMP. Analista de Promotoria I- Assistente Social do Ministério Público do Estado de São Paulo - Regional Campinas. E-mail: andreiabarboza@mpsp.mp.br.

${ }^{2}$ Bacharel em Direito formado pela Pontifícia Universidade Católica de Campinas, PUC Campinas, Promotor de Justiça Substituto do Ministério Público do Estado de São Paulo. E-mail: tiagobarboza@mpsp.mp.br.

Serv. Soc. \& Saúde, Campinas, SP v. 13, n. 2 (18) p. 205-224 jul./dez. 2014 ISSN 1676-6806
} 


\section{INTRODUÇÃO}

Diferentemente do costumeiro, começamos este trabalho com uma conclusão, que decorre de curta, mas rica experiência profissional: A maturidade de nosso Estado Democrático e Social de Direito passa, necessariamente, por um Ministério Público independente e efetivo, que desenvolva a contento suas potencialidades.

Quais potencialidades? O artigo 127 da Constituição Federal afirma que o Ministério Público é instituição essencial à Justiça e a ele cabe, em síntese, a defesa da ordem jurídica, do regime democrático e dos interesses individuais e sociais indisponíveis.

Trata-se, portanto, de ministério público e social.

Pois bem, a Constituição Federal de 1988, a "Constituição Cidadã”, é fruto de período pós-ditatorial e, como consequência, pródiga em garantias formais, tanto individuais quanto coletivas e sociais.

Além disso, trata-se de legislação ostensiva na definição de normas de conteúdo programático e:

[...] na medida em que o Estado normatiza programas de ação governamental, elegendo fins socialmente desejáveis e subordinandoos à retórica dos direitos, todo o arsenal institucional do direito liberal, dentre eles a dogmática jurídica e o primado da inafastabilidade da revisão judicial, passa a ser posto a serviço da efetivação desses novos compromissos (ou direitos). (BADÍN, 2013, p. 155).

Tanto que os direitos sociais chegam a ser chamados por doutrinadores de “direitos de crédito" (LIBERATTI, 2013, p. 77-78), pois compõem-se de um conjunto de direitos que exigem a realização de autênticas prestações de serviços por parte do Estado.

E é por meio de políticas públicas que os Poderes Públicos devem realizar os objetivos fundamentais previstos no artigo $3^{\circ}$ da Constituição Federal (1988):

\footnotetext{
I - construir uma sociedade livre, justa e solidária,

II - garantir o desenvolvimento nacional,

III - erradicar a pobreza e a marginalização e reduzir as desigualdades sociais e regionais,

IV - promover o bem de todos, sem preconceitos de origem, raça, sexo, cor, idade e quaisquer outras formas de discriminação.
}

Políticas Públicas são formas de programa de ação governamental ou "o conjunto de atividades do Estado tendentes a seus fins, de acordo com metas a serem atingidas" (CANELA JÚNIOR, 2011, p. 88-89).

Serv. Soc. \& Saúde, Campinas, SP v. 13, n. 2 (18) p. 205-224 jul./dez. 2014 ISSN 1676-6806 
Ou seja, a partir do momento em que o legislador expressamente previu programas e fins sociais, a inafastabilidade da jurisdição permite que se exija, judicialmente, o atingimento dos objetivos sociais traçados pelo constituinte de 1988. Trata-se da chamada "judicialização da política e da politização do judiciário" (MANCUSO, 2011, p. 80).

O Estado prestador de serviços rompe com sua passividade e visa cumprir mandamento constitucional de prestar os serviços essenciais garantidores da cidadania social e da democracia cidadã. Neste caso, omissão significa afronta ao regime democrático.

Conclui-se também que a Lei Máxima de 1988 concedeu ao Ministério Público papel de destaque e um verdadeiro arsenal de poderes, explícitos e implícitos (promover ações judiciais, instaurar procedimentos investigatórios, exigir ajustamento de condutas de órgãos públicos às exigências legais, expedir recomendações, dentre outros). A finalidade mais nobre é uma: dar concretude a garantias que hoje estão apenas no papel.

Importante ressaltar que a Carta Maior $^{3}$ veio a lume apenas três anos depois da Lei da Ação Civil Pública ${ }^{4}$, idealizada por representantes do Ministério Público do Estado de São Paulo e que previu a tutela coletiva de direitos, quais sejam, os direitos "transindividuais" (que extrapolam a individualidade e estão difusos na sociedade, tais como saúde, educação, consumidor, meio ambiente, patrimônio público, idoso, portador de deficiência).

Foi neste ambiente - num Estado Pós-Social - que o Ministério Público, órgão apartado dos três Poderes de Estado discriminados por Montesquieu ${ }^{5}$ (2000, p. 75 et seq.), ganhou corpo e protagonismo.

Podemos afirmar que o protagonismo do Ministério Público se dá pela atrofia e pela ineficiência dos demais Poderes na concretização dos direitos sociais e garantias individuais e coletivas.

Tanto que matéria veiculada no Jornal Estado de São Paulo em 10 de novembro de 2014 aponta o Ministério Público como a terceira instituição com maior credibilidade no país, atrás apenas das Forças Armadas e da Igreja Católica, e bem à frente dos

\footnotetext{
${ }^{3}$ Constituição Federal (1988).

${ }^{4}$ Lei n ${ }^{0} 7347 / 85$-Disciplina a ação civil pública de responsabilidade por danos causados ao meioambiente, ao consumidor, a bens e direitos de valor artístico, estético, histórico, turístico e paisagístico (VETADO) e dá outras providências. Disponível em: http://www.planalto.gov.br/ccivil_03/leis/ 17347orig.htm Acesso em 04 nov. 2014.

5 Teoria da separação de poderes: legislativo, executivo e judiciário.

Serv. Soc. \& Saúde, Campinas, SP v. 13, n. 2 (18) p. 205-224 jul./dez. 2014 ISSN 1676-6806
} 
Poderes Legislativo, Executivo e Judiciário (conforme pesquisa oriunda da Escola de Direito da FGV, intitulada "Índice de Confiança na Justiça no Brasil") 6.

Num país jovem, com democracia em desenvolvimento e com poucos canais efetivos de exercício da cidadania, perguntamo-nos como os anseios da sociedade serão assimilados e defendidos ativamente?

A partir disso e cientes de que a legitimidade do Ministério Público como instituição essencial à Justiça está na tutela dos interesses de nossa sociedade multicultural, passou a prevalecer entendimento dos Promotores de Justiça de que nosso desafio é sermos agentes de transformação social, promovendo a concretização, inclusive extrajudicialmente, de direitos sociais e garantias fundamentais individuais e coletivas. Tanto que no Ministério Público do Estado de São Paulo são de vanguarda o "Núcleo de Políticas Públicas" (NPP) 7 e a "Rede Protetiva de Direitos Sociais" $(\mathrm{RAPDS})^{8}$.

A respeito, vale dizer que:

[...] a efetividade significa a realização do Direito, o desempenho concreto de sua função social. Ela representa a materialização, no mundo dos fatos, dos preceitos legais e simboliza a aproximação, tão íntima quanto possível, do dever-ser normativo e o ser da realidade social (BARROSO, 2013, p. 82-83).

Mais:

\footnotetext{
${ }^{6}$ Disponível em: http://fgvnoticias.fgv.br/pt-br/noticia/pesquisa-do-icjbrasil-avalia-confianca-nasinstituicoes-do-estado Acesso em 10 nov.2014.

${ }^{7}$ Núcleo de Políticas Públicas (NPP) do MP/SP- Missão:

-produzir estudos e análises sobre a quantidade, eficácia e efetividade das políticas públicas voltadas à implementação dos direitos sociais;

- contribuir na elaboração e desenvolvimento do Plano Geral de Atuação do Ministério Público;

- incentivar e apoiar a elaboração dos Programas Regionais e Locais de Atuação do Ministério Público; - formar a rede de apoio externo à atuação do Ministério Público, mediante contato com a comunidade científica e a sociedade civil;

- estimular a fixação de estratégias de atuação do Ministério Público, inclusive mediante integração entre os diversos órgãos de execução, em ambas as instâncias;

- orientar os Programas de Atuação Integrada e os Projetos Especiais;

- avaliar periodicamente o atingimento das metas dos Programas de Atuação do Ministério Público.

Disponível em: http://www.mpsp.mp.br/portal/page/portal/Nucleo_Politicas_Publicas Acesso em 10 nov.2014.

${ }^{8}$ Rede Protetiva de Direitos Sociais - MP/SP: O Núcleo 1 da Rede Protetiva de Direitos Sociais tem por finalidade tratar de problemas regionais recorrentes e de difícil solução. Após várias discussões e reuniões com Promotores da região, constatou-se a necessidade de se atuar em três frentes: 1) moradores de rua, 2) saúde mental/ álcool e drogas; 3) agentes ambientais (coleta seletiva, reciclagem, catadores de lixo etc. Atualmente, o núcleo 1 da rede protetiva de direitos sociais é formado por 19 Promotores de Justiça, abrangendo 35 cidades. As questões acima são discutidas e debatidas de maneira regionalizada, sempre respeitando o princípio do Promotor Natural. Visa-se o trabalho integrado. Disponível em: http://www.mpsp.mp.br/portal/page/portal/cao_criminal/Boas_praticas/Relacao_Projetos/rede_protetiva/r ede\%20protetivas.htm Acesso em 10 nov. 2014.
}

Serv. Soc. \& Saúde, Campinas, SP v. 13, n. 2 (18) p. 205-224 jul./dez. 2014 ISSN 1676-6806 
[...] em oposição ao individualismo excludente, o espírito da nova civilização há de ser a irradiação da fraternidade universal, a organização de uma humanidade solidária. Sendo objetivo da justiça proporcional ou distributiva instaurar a igualdade substancial de condições de vida, é óbvio que ela só pode realizar-se por meio de políticas públicas ou programas de ação governamental (COMPARATO, 2010, p. 553).

O lugar ocupado pelo Ministério Público no Estado Brasileiro PósConstitucionalista é desafiador, pedindo responsabilidade e empenho. Nesta Instituição a população brasileira deposita esperança.

Por todo o exposto derivou a conclusão de que o atingimento de nossos objetivos - notadamente a concretização de direitos individuais e sociais por meio de políticas públicas, requer o bom trato de conhecimentos multidisciplinares, que exorbitam a ciência estritamente jurídica, eis que um Promotor de Justiça não pode, por exemplo, promover ou tutelar o bom funcionamento dos Sistemas Públicos de Saúde, Educação e Assistência Social sem o amparo da expertise de "outros técnicos".

Para tanto, impulsionado pela necessidade de aprimoramento da atuação institucional, o Ministério Público paulista criou o "Núcleo de Apoio Técnico" (NAT), formado por duplas psicossociais que ocupam todas as sedes regionais da instituição e tem como atribuição precípua o assessoramento técnico aos membros do Ministério Público na identificação de demandas alusivas à materialização de políticas públicas e no diagnóstico regionalizado dos principais problemas sociais a serem enfrentados pelas Promotorias de Justiça.

\section{Serviço Social no Ministério Público}

O Serviço Social foi implementado no Ministério Público do Estado de São Paulo em 2005 por meio de concurso público. Ingressaram 11 assistentes sociais até o período de 2011. Dentre esses, sete assistentes sociais foram designados para o Centro de Apoio Operacional as Promotorias de Justiça Cíveis e de Tutela Coletiva $(\mathrm{CAO})^{9}$ e quatro foram designados para o Grupo de Atuação Especial de Enfretamento à Violência Doméstica (GEVID).

\footnotetext{
${ }^{9}$ Centro de Apoio Operacional as Promotorias de Justiça Cíveis e de Tutela Coletiva (CAO): Como órgão auxiliar da atividade funcional do Ministério Público, incumbe ao Centro de Apoio o exercício de atividades indutoras da política institucional, notadamente estimulando a integração e o intercâmbio entre os órgãos de execução que atuem na mesma área de atividade e que tenham atribuições comuns. Disponível em: http://www.mpsp.mp.br/portal/page/portal/CAO\%20Tutela Acesso 28 nov. 2014 Serv. Soc. \& Saúde, Campinas, SP v. 13, n. 2 (18) p. 205-224 jul./dez. 2014 ISSN 1676-6806
} 
A fase inicial do trabalho dos assistentes sociais do Centro de Apoio (CAO Cível) teve como atribuições análises de processos individuais, atendimentos aos servidores, avaliações de serviços de acolhimento institucional para crianças e adolescentes e serviços de medida em meio aberto (Liberdade Assistida e Prestação de Serviço à Comunidade), além de apoio técnico aos promotores de justiça.

Todavia, com o crescimento e fortalecimento do Serviço Social no MP/SP, as atribuições do assistente social voltaram-se para a avaliação de políticas sociais, assessorando os promotores de justiça na defesa dos direitos e interesses coletivos.

Os assistentes sociais realizam assim uma ação de cunho socioeducativo na prestação de serviços sociais, viabilizando o acesso aos direitos e aos meios de exercê-los, contribuindo para que necessidades e interesses dos sujeitos sociais adquiram visibilidade na cena pública e possam ser reconhecidos, estimulando a organização dos diferentes segmentos dos trabalhadores na defesa e ampliação dos seus direitos, especialmente os direitos sociais. Afirma o compromisso com os direitos e interesses dos usuários, na defesa da qualidade dos serviços sociais (IAMAMOTO, 2009, p. 19).

A construção das novas atribuições do Serviço Social ${ }^{10}$ dentro do MP/SP foi inspirada na atuação no âmbito do Ministério Público do Espírito Santo, voltadas para avaliações de políticas públicas. A partir de encontros entre assistentes sociais de Ministérios Públicos de outros estados, no MP/SP iniciou-se análise das funções dentro do Ministério Público e da legitimação do papel do assistente social enquanto agente de transformação social na instituição.

No IV Encontro Nacional do Serviço Social no Ministério Público que aconteceu em 2012, no Rio de Janeiro, os técnicos do MP/ES informaram que suas atribuições retrocederam, perdendo a ênfase na avaliação de políticas sociais. Este fato revela a necessidade do constante movimento dos assistentes sociais na defesa de seu papel dentro do Ministério Público e a consciência do inacabamento (FREIRE, 1999).

\section{NAT - Núcleo de Assessoria Técnica Psicossocial}

Em janeiro de 2012, por meio do ato normativo $n^{\circ} 724 \mathrm{MP} / \mathrm{SP}$, foi criado o Núcleo de Assessoria Técnica Psicossocial (NAT), com coordenação técnica e sem ligação a nenhuma promotoria específica. O NAT foi implantado em São Paulo e nas 12

\footnotetext{
${ }^{10} \mathrm{O}$ fortalecimento do trabalho do assistente social no MP/SP e construção de novas atribuições é apresentado detalhadamente por ARRUDA (2014), assistente social que ingressou no primeiro concurso, coordenadora do NAT no período de janeiro de 2012 a novembro de 2014.

Serv. Soc. \& Saúde, Campinas, SP v. 13, n. 2 (18) p. 205-224 jul./dez. 2014 ISSN 1676-6806
} 
regionais do MP/SP a partir do ingresso de novos assistentes sociais e psicólogos pelo concurso público realizado em 2011, com as seguintes atribuições:

I - avaliar políticas públicas sociais, planos, programas e projetos relativos às matérias de Serviço Social e Psicologia dos órgãos da Administração Direta ou Indireta do Estado e dos Municípios, organizações da sociedade civil, movimentos sociais e Conselhos de Direitos, sugerindo medidas para implementação ou reordenamento das políticas já existentes; Área de Documentação e Divulgação do Ministério Público do Estado de São Paulo;

II - planejar, executar e avaliar pesquisas dos órgãos da Administração Direta ou Indireta do Estado e dos Municípios, organizações da sociedade civil, movimentos sociais e Conselhos de Direitos que possam contribuir para a análise da realidade social e para subsidiar ações e decisões no âmbito do Ministério Público do Estado de São Paulo;

III - mapear recursos da rede de serviços socioassistenciais de saúde, educação, habitação, trabalho, esporte, cultura, lazer e demais políticas públicas para subsidiar as atividades próprias dos órgãos de execução do Ministério Público do Estado de São Paulo.

Com a extensão do quadro da equipe técnica na capital, dividiu-se a atuação de alguns técnicos por área. Já em cada área regional, uma dupla psicossocial inseriu o trabalho do NAT, prestando assessoria técnica aos promotores de justiça com atribuições vinculadas à área da Infância e Juventude; Direitos Humanos, com abrangência na defesa do idoso, da pessoa com deficiência, inclusão social, violência contra a mulher e saúde pública, Educação; Meio ambiente; Habitação ${ }^{11}$ e Urbanismo.

O MP/SP incentiva a participação dos técnicos em seminários, capacitações e encontros, autorizando a ausência dos técnicos em seus postos. Trimestralmente são realizados encontros com toda equipe técnica do estado na cidade de São Paulo para discussão de demandas e temas, trocas de experiências, com palestrantes externos. Com o mesmo fim, a equipe mantém constante contato em um grupo de e-mails para suporte técnico.

\begin{abstract}
A atuação no campo das políticas sociais pressupõe, dos profissionais, qualificação teórico-metodológica, ético-política e técnico-operativa, para não cair no tecnicismo, promovendo avaliações descontextualizadas, imediatas e aparentes das inúmeras expressões da questão social (ARRUDA, 2014, p. 156).
\end{abstract}

\footnotetext{
${ }^{11}$ Há uma assistente social do NAT alocada em São Paulo que atende as solicitações da área de habitação. Serv. Soc. \& Saúde, Campinas, SP v. 13, n. 2 (18) p. 205-224 jul./dez. 2014 ISSN 1676-6806
} 
Devido às diversas áreas de atuação do assistente social do MP/SP, requer-se qualificação profissional aprofundada em múltiplos setores, apropriação de todas as legislações vigentes e aprofundamento da compreensão de saberes (FREIRE, 1999) indispensável ao exercício profissional. A capacitação constante é inerente ao bom desempenho do trabalho, no tocante a desmistificações de demandas desafiadoras e díspares que se apresentam. Além disso, o profissional deve estar preparado para realizar visitas de inspeções que "exigem profissionalismo, estudo do Estatuto e respeito aos visitados, incluindo os dirigentes da instituição. Implica, mais uma vez, cuidado em não julgar, mas somente avaliar" (MAGALHÃES, 2003, p. 56).

É importante destacar que a atuação do assistente social no MP/SP é inserida na avaliação constante de políticas sociais. O profissional dentro de um espaço sócio jurídico trabalha com desafios que demandam análises, discussões e capacitação para desenvolver técnicas-metodológicas, visando realizar "avaliação de políticas sociais que se situe na compreensão do significado do papel do Estado e das classes sociais na construção dos direitos e da democracia” (BOSQUETTI, 2009, p. 580), não meramente na efetividade de programas em solucionar questões pontuais.

Ao contrário, a avaliação de políticas sociais públicas deve ser orientada pela intencionalidade de apontar em que medida as políticas e programas sociais são capazes e estão conseguindo expandir direitos, reduzir a desigualdade social e propiciar a equidade (BOSQUETTI, 2009, p. 579).

\section{Área Regional de Campinas}

A área regional de Campinas ${ }^{12}$ abrange 51 municípios, em 37 comarcas. A assessoria técnica da dupla psicossocial é realizada por meio de solicitações que os promotores de justiça enviam à Coordenadora Técnica do NAT.

Segue quadro com a porcentagem das visitas realizadas do mês de janeiro a outubro de 2014.

\footnotetext{
12 Comarcas: Aguaí, Águas de Lindóia, Amparo, Artur Nogueira, Atibaia, Bragança Paulista, Campinas, Conchal, Cosmópolis, Espírito Santo do Pinhal, Hortolândia, Indaiatuba, Itapira, Itatiba, Itupeva, Jaguariúna, Jarinu, Jundiaí, Louveira, Mogi Guaçu, Mogi Mirim, Nazaré Paulista, Nova Odessa, Paulínia, Pedreira, Pinhalzinho, Piracaia, São João da Boa Vista, Serra Negra, Socorro, Sumaré, Valinhos, Vargem Grande do Sul, Várzea Paulista e Vinhedo - Munícipios sem promotoria: Águas da Prata, Bom Jesus dos Perdões, Engenheiro Coelho, Estiva Gerbi, Holambra, Joanópolis, Lindóia, Monte Alegre do Sul, Morungaba, Pedra Bela, Santo Antônio da Posse, Santo Antônio do Jardim, Tuiuti e Vargem. Serv. Soc. \& Saúde, Campinas, SP v. 13, n. 2 (18) p. 205-224 jul./dez. 2014 ISSN 1676-6806
} 


\begin{tabular}{l|c}
\hline SOLICITAÇÃO ÁREA REGIONAL CAMPINAS & QUANTIDADE \\
\hline Medida Sócio Educativa (MSE) em meio fechado & $38,09 \%$ \\
\hline Comunidade Terapêutica & $26,19 \%$ \\
\hline Instituição de Longa Permanência para Idosos (ILPI) & $11,90 \%$ \\
\hline Acolhimento Institucional & $9,52 \%$ \\
\hline Conselho Tutelar & $4,76 \%$ \\
\hline Hospital & $2,38 \%$ \\
\hline Medida Socioeducativa (MSE) em meio aberto & $2,38 \%$ \\
\hline Políticas Públicas & $2,38 \%$ \\
\hline Serviço Saúde Mental & $2,38 \%$ \\
\hline
\end{tabular}

Fonte: *Levantamento realizado pela Equipe do Núcleo de Assessoria Técnica da Capital

No início da execução do trabalho do NAT na regional de Campinas, as maiores demandas se apresentavam na área da Infância e Juventude, principalmente solicitações de acompanhamento aos promotores de justiça em visitas de inspeções periódicas ${ }^{13,} 14$ (função fiscalizadora do promotor), em serviços de acolhimento institucional para crianças e adolescentes e serviços de medida socioeducativa em meio fechado.

Em alguns municípios a dupla psicossocial acompanhava o promotor de justiça em quatro visitas na mesma instituição durante o ano. Com as novas demandas em outras áreas e a falta de disponibilidade para atender outros municípios, concluiu-se que para efetividade da equipe do NAT em toda área regional, as visitas institucionais teriam melhor aproveitamento sendo realizadas anualmente. Verificou-se também que a maioria das visitas realizadas no mesmo local em curto espaço de tempo não apresentava mudanças pertinentes para o parecer social e psicológico. Diante desses fatores, foi acordado com os promotores que as visitas com o NAT devem ser efetuadas anualmente. Porém em situações de denúncias ou emergências, a visita é imprescindível, mesmo que já tenha sido feita no mesmo ano.

\footnotetext{
${ }^{13}$ Segundo o Art. 95 do ECA, O Ministério Público tem função fiscalizadora dos serviços destinados a crianças e adolescentes: "As entidades governamentais e não-governamentais referidas no art. 90 serão fiscalizadas pelo Judiciário, pelo Ministério Público e pelos Conselhos Tutelares”.

${ }^{14}$ As visitas de inspeção "tem como finalidade verificar se o trabalho desenvolvido nas instituições, bem como suas instalações físicas, atendem aos objetivos aos quais elas se destinam” (MAGALHÃES, 2009, p. 56).

Serv. Soc. \& Saúde, Campinas, SP v. 13, n. 2 (18) p. 205-224 jul./dez. 2014 ISSN 1676-6806
} 


\section{PRINCIPAIS DEMANDAS NA ÁREA REGIONAL DE CAMPINAS}

Para compreender a amplitude da atuação do NAT no MP/SP à luz do trabalho do Serviço Social, serão apresentadas brevemente as principais solicitações dos promotores de justiça da área regional de Campinas.

\section{- Infância e Juventude}

Nos anos de 2012 e 2013, as maiores demandas apresentadas à dupla psicossocial da área regional de Campinas do Ministério Público foram da área da Infância e Juventude, em acompanhamento de visitas aos serviços de acolhimento institucional para crianças e adolescentes ${ }^{15}$ e serviços de medida socioeducativo em meio fechado. Em 2014 as visitas em serviços de medida socioeducativa em meio fechado se destacaram em primeiro lugar entre as solicitações, mas em serviços de acolhimento institucional houve notável diminuição.

O assistente social do MP observa o trabalho do Serviço Social como um todo durante as visitas em serviços da área da Infância e Juventude. A atuação nestes serviços pode ser decisiva na tomada de decisões dos promotores de justiça em processos individuais, assim como na avaliação do trabalho da Instituição. Dessa forma, é necessário que a coleta de dados e a observação do MP sejam realizadas com um olhar crítico para apreensão de como se dá o desenvolvimento do trabalho do Serviço Social.

$\mathrm{O}$ assistente social do MP/SP tem o cuidado de esclarecer o papel de assessoria técnica durante as visitas e elaborar o parecer técnico fundamentado no Código de Ética do Assistente Social ${ }^{16}$.

Os relatórios de inspeção devem contar, em seus registros, com a exposição e a descrição daquilo que foi observado no decorrer da

\footnotetext{
${ }^{15}$ É previsto na resolução $n^{\circ} 71$ do Conselho Nacional do Ministério Público (CNMP), de 15 de junho de 2011 assessoria técnica aos promotores em inspeções em serviços de acolhimento institucional e familiar no artigo $1^{\circ}$ : $\S 4^{\circ}$. Os profissionais de Serviço Social, Psicologia e Pedagogia devem prestar assessoria técnica ao membro do Ministério Público na matéria de sua especialidade, com o objetivo de monitorar e avaliar a qualidade do atendimento prestado pelos serviços de acolhimento para o público infanto-juvenil, observando-se, prioritariamente, os seguintes critérios para a solicitação de seus serviços:

I. Situações que demandem assessoria no processo de reordenamento dos serviços de acolhimento; II. Situações que demandem assessoria no processo de articulação entre os serviços de acolhimento e os responsáveis pela política de atendimento; III. Situações em que se dá o planejamento da implantação de serviços de acolhimento nos municípios; IV. Situações que demandem a avaliação dos serviços de acolhimento no contexto da política para a infância e juventude. Disponível em:

http://www.cnmp.mp.br/portal/images/stories/Destaques/Publicacoes/Res_71_VOLUME_1_WEB_.PDF Acesso em: 20 nov. 2014.

${ }^{16}$ Código de Ética do/a Assistente Social - Disponível em: http://www.cfess.org.br/arquivos/CEP_CFESS-SITE.pdf Acesso em 23 out. 2014.

Serv. Soc. \& Saúde, Campinas, SP v. 13, n. 2 (18) p. 205-224 jul./dez. 2014 ISSN 1676-6806
} 
visita. Devem ainda incluir um parecer profissional sobre a questão avaliada, como, por exemplo: as providências a serem tomadas, as possiblidades viáveis do que pode ser feito para dirimir possíveis falhas e a consonância - ou não - do trabalho desenvolvido com os objetivos que pretende alcançar. No caso específico de instituições que trabalhem com crianças e adolescentes, esses objetivos precisam estar coadunados com o Estatuto da Criança e do Adolescente (MAGALHÃES, 2003, p. 65).

As metodologias e instrumentais utilizados pelos profissionais dos serviços são respeitados. Nos pareceres sociais, quando necessário, é indicada a importância de alguns instrumentais inerentes ao exercício profissional, como visitas domiciliares, elaboração do Plano Individual de Atendimento (PIA) embasado na estrutura e realidade familiar, e principalmente, do sujeito em questão. As ações e todos os desdobramentos da atuação dos assistentes sociais nas instituições permitem ao promotor de justiça aglutinar informações das crianças/adolescentes e da família para traçar suas deliberações.

Os pareceres sociais são ancorados em leis, resoluções e orientações técnicas que devem ser seguidas. Nas visitas são realizadas reuniões entre o NAT e promotores de justiça com a equipe técnica para esclarecimentos de dúvidas e orientações que são solicitadas ou que o MP/SP entenda necessárias. Também são realizadas reuniões em locais já visitados para discussão do parecer psicossocial anterior e devolutiva dos pontos que foram analisados.

\section{- Idoso}

Outra solicitação que é apresentada costumeiramente para a equipe do NAT da Regional de Campinas é o acompanhamento junto aos promotores em visitas de inspeções em ILPI - Instituição de Longa Permanência para Idoso e Casas de Repouso para Idoso.

O parecer social se fundamenta, dentre outras normativas, na Política Nacional do Idoso, no Estatuto do Idoso e no NOB-RH/SUAS, que indica equipe técnica de referência para atendimento direto ${ }^{17}$ em instituições que acolhem idosos. Os grandes

\footnotetext{
${ }^{17}$ NOB RH /SUAS: Equipe de Referência para atendimento direto - 1 Coordenador (nível superior ou médio); Cuidadores (nível médio); 1 Assistente Social; 1 Psicólogo; 1 Profissional para desenvolvimento de atividades socioculturais (nível superior); Profissional de Limpeza (nível fundamental); Profissional de alimentação (nível fundamental); Profissional de lavanderia (nível fundamental).

Serv. Soc. \& Saúde, Campinas, SP v. 13, n. 2 (18) p. 205-224 jul./dez. 2014 ISSN 1676-6806
} 
desafios nas visitas são avaliações dos serviços que são oferecidos, equipe de funcionários e o Grau de Dependência ${ }^{18}$ dos idosos que estão acolhidos no local.

Assim como a Vigilância Sanitária do Estado de São Paulo considera a ILPI como equipamento social, tendo como referência a Resolução SS 123/2001 ${ }^{19}$ que define e classifica as Instituições Geriátricas, diferenciando ILPI das Casas de Repouso, o NAT tem considerado esta resolução para a elaboração dos pareceres, assim como indicações dos serviços que devem ser oferecidos ao idoso e equipe mínima para atendê-los. A Classificação Nacional de Atividade Econômica (CNAE) ${ }^{20}$, assim como a resolução SS 123/2001, também distinguem as instituições de atenção à pessoa idosa.

De acordo com as irregularidades que são identificadas em visitas de inspeção, é sugerido nos pareceres que os promotores de justiça solicitem relatórios de serviços de fiscalização de cada setor específico, como Vigilância Sanitária, COREN - Conselho

\footnotetext{
${ }^{18}$ ANVISA - RDC n ${ }^{\circ}$ 283: 4.6.1.2 - Para os cuidadores residentes: a) Grau de Dependência I: um cuidador para cada 20 idosos, ou fração, com carga horária de 8 horas/dia; b) Grau de dependência II: um cuidador para cada 10 idosos, ou fração, por turno; c) Grau de Dependência III: um cuidador para cada 6 idosos, ou fração, por turno. Disponível em:

http://www.anvisa.gov.br/hotsite/segurancadopaciente/documentos/rdcs/RDC\%20N\%C2\%BA\% 20283-2005.pdf . Acesso em 4 fev. 2014.

${ }^{19}$ Resolução SS - 123, de 27-9-2001- Define e Classifica as Instituições Geriátricas no âmbito do Estado de São Paulo e dá providências correlatas: Capítulo IV - Da Classificação das Instituições Geriátricas e Similares [...]Artigo 12- Os estabelecimentos referidos nos incisos e nas alíneas do artigo anterior, os quais são objeto de denominações diversas, para os efeitos desta Resolução serão assim denominados: I estabelecimentos de assistência à saúde que se destinam, centralmente, à prestação de serviços de assistência médica às pessoas idosas, em regime de atendimento ou assistência asilar: CASA DE REPOUSO; II estabelecimentos de interesse à saúde que se destinam, centralmente, à prestação de serviços de assistência social, em regime de atendimento ou assistência asilar: ASILO; [...] Disponível em: http://www.mpsp.mp.br/portal/page/portal/cao_civel/aa_idoso/aa_ido_legislacao/aa_ido_legislacao_estad ual/Resolu\%C3\%A7\%C3\%A3o\%20SS\%20n\%20123\%20de\%2027\%2009\%202001\%20define \%20e\%20 classifica\%20Institui\%C3\%A7\%C3\%B5es\%20geri\%C3\%A1tricas.pdf Acesso em 4 fev. 2014

${ }^{20}$ Classificação oficial adotada pelo Sistema Estatístico Nacional do Brasil e pelos órgãos federais, estaduais e municipais gestores de registros administrativos e demais instituições do Brasil. Com base na resolução do presidente do IBGE n 054 , de 19 de dezembro de 1994, publicada no Diário Oficial da União no 244, em 26 de dezembro 1994, vem sendo implementada desde 1995 pelo Sistema Estatístico Nacional e órgãos da administração federal. As Casas de Repousos para idosos estão classificadas na CNAE 2.1 Subclasse 8711-5/01 - Clínicas e Residências Geriátricas que compreende: o fornecimento de serviços em clínicas e residências geriátricas ou domicílios coletivos para idosos que não têm condições de saúde e/ou não desejam viver de forma independente. A infraestrutura oferecida por estes locais, inclui além do fornecimento de alojamento e alimentação, cuidados médicos e psicológicos, serviços de enfermagem e de acompanhantes. Disponível em: http://www.cnae.ibge.gov.br/ Acesso 15 ago. 2013. As ILPISs estão classificadas na CNAE 2.1 - Subclasse 8711-5/02 - Instituições de Longa Permanência para Idosos que compreende - as atividades de assistência social a idosos sem condições econômicas para se manterem prestadas em estabelecimentos públicos, filantrópicos ou privados (asilos) equipados para atender a necessidades de alojamento, alimentação, higiene e lazer. Estes estabelecimentos podem oferecer cuidados médicos esporádicos. Não sendo um elemento central desse atendimento. Disponível em: http:// www.cnae.ibge.gov.br/ Acesso 15 ago. 2013.
}

Serv. Soc. \& Saúde, Campinas, SP v. 13, n. 2 (18) p. 205-224 jul./dez. 2014 ISSN 1676-6806 
Regional de Enfermagem do Estado de São Paulo, dentre outros pertinentes para complementação da fiscalização.

O Serviço Social do MP/SP busca inteirar-se das funções do assistente social dentro destas instituições, além da metodologia e instrumentais utilizados. Os estudos sociais e encaminhamentos na rede intersetorial, descritos nos relatórios sociais destinados ao Ministério Público, também tem caráter imprescindível e decisivo nos processos de proteção ao idoso. É recomendada à equipe técnica a articulação com a rede de assistência social, previdência social e saúde, que formam o tripé da seguridade social, garantidos na Constituição Federal (BRASIL, 1988).

A experiência tem identificado casos de violação aos direitos do idoso. Os promotores de justiça valorizam a atuação e relatórios dos assistentes sociais em cada serviço da rede intersetorial para o andamento de casos individuais e avaliações institucionais. De acordo com Magalhães, os relatórios assumem "um papel de intervenção indireta, pois, a partir do seu conteúdo, providências e decisões são tomadas, ou até mesmo "vidas" são definidas" (2003, p. 58).

\section{- Assistência Social}

As demandas de avaliação de Políticas Públicas estão relacionadas principalmente a implementação da rede de assistência social do Sistema Único de Assistência Social (SUAS). Em geral, os promotores de justiça solicitam que a equipe do NAT avalie em seu município de atuação os equipamentos existentes.

O NAT inicia o processo de avaliação da rede de assistência social realizando um mapeamento dos equipamentos implantados nos municípios. Após essa fase, os equipamentos são visitados, municipais ou ONGs cofinanciadas, para apropriação dos serviços disponibilizados, espaços de acordo com as regulamentações, materiais e instrumentos de trabalho, e localização em território diagnosticado com maiores vulnerabilidades, além da acessibilidade aos usuários.

Nas visitas é possível reunir-se com a equipe técnica para apresentação das principais atividades e ações que são desenvolvidas, planos e projetos que atendam às demandas das famílias de cada território, com foco nas principais vulnerabilidades sociais diagnosticadas pela equipe. 
A "elaboração de diagnósticos integrados das realidades municipais e locais" (RAICHELIS, 2009) são embasados nas normativas elencadas na Política Nacional de Assistência Social e na Norma Operacional Básica do Sistema Único de Assistência Social - NOB/SUAS (BRASIL, 2012), para apontamentos técnicos do funcionamento dos serviços da rede de assistência social.

Os diagnósticos que foram realizados pelo NAT identificaram a crescente terceirização de serviços que deveriam ser de natureza público-estatal. Os pareceres do Serviço Social sustentam que os serviços executados pelo poder público visam garantir a continuidade da equipe de funcionários públicos, propiciando proximidade e vínculo com os familiares que são atendidos, apropriação dos serviços e das vulnerabilidades do território que o serviço está alocado e maior efetividade dos investimentos em capacitação continuada. A mudança constante de funcionários em serviços que são cofinanciados podem prejudicar o trabalho construído no território e estar entre as razões da falta de adesão dos usuários. Segundo RAICHELIS (2009, p. 384):

As consequências dessa forma de condução das políticas públicas para o trabalho social são profundas, pois a terceirização desconfigura o significado e a amplitude do trabalho técnico realizado pelos assistentes sociais e demais trabalhadores sociais, desloca as relações entre a população, suas formas de representação e a gestão governamental, pela intermediação de empresas e organizações contratadas; além disso, as ações desenvolvidas passam a ser subordinadas a prazos contratuais e aos recursos financeiros destinados para esse fim, implicando descontinuidades, rompimento de vínculos com usuários, descrédito da população para com as ações públicas.

As políticas públicas passam a se caracterizar por repasses de recursos financeiros, esvaziando o significado do serviço público para a população. A terceirização tem sido praticada também em outras áreas, sucateando os serviços públicos.

\section{- Saúde Pública - Rede de Atenção Psicossocial em Saúde Mental}

Além das solicitações pelos promotores de justiça de diagnóstico na rede de assistência social, têm sido crescentes as solicitações de mapeamento da rede de saúde mental na área regional de Campinas. Segue-se o mesmo caminho, realizando-se o mapeamento dos serviços ofertados pela saúde nos municípios, visitas e reuniões com a equipe técnica.

Serv. Soc. \& Saúde, Campinas, SP v. 13, n. 2 (18) p. 205-224 jul./dez. 2014 ISSN 1676-6806 
Os pareceres do Serviço Social direcionam o reordenamento de serviços de atenção psicossocial e quantidade que devem ser ofertados a população de acordo com o porte do município, equipe mínima, instrumentos de trabalho adequados, espaços, território e acessibilidade aos usuários. As diretrizes no atendimento em saúde mental e a Rede de Atenção Psicossocial (RAPS) instituída pela Portaria federal 3088/12 ${ }^{21}$ são utilizadas para o embasamento dos pareceres psicossociais.

No contexto mudancista novos processos de trabalho são requeridos exigindo novas técnicas e tecnologias e novas formas de trabalho em saúde e, particularmente em saúde mental, calcadas no trabalho em equipe multiprofissional e interdisciplinar, no território de vida da pessoa enferma, atuação em rede sócio assistencial, intersetorial, calcada no controle social, na promoção da cidadania e da autonomia possível de usuários e familiares (ROSA; MELO, 2009, p. 83).

Concomitantemente à preocupação da implantação dos serviços da rede de saúde mental, muitos promotores de justiça voltaram suas atenções para as comunidades terapêuticas e clínicas, sendo a maioria delas particulares e que estão sendo utilizadas por diversos gestores públicos como "retaguarda" para internação de usuários de substâncias psicoativas.

Na maioria das Comunidades Terapêuticas visitadas, estão sendo realizadas internações voluntárias, involuntárias e compulsórias. Ressalta-se nos pareceres do Serviço Social que tratamentos em comunidades terapêuticas devem ser voluntários. Entende-se também que as internações involuntárias e compulsórias devem ser realizadas em leitos hospitalares ou clínicas com equipe médica e de enfermagem em tempo integral. Qualquer internação, voluntária, involuntária ou compulsória, deve ser avaliada e realizada conforme a Lei $10.216 / 2001^{22}$.

Diversas situações de violações de direitos humanos têm se apresentado nas visitas em comunidades terapêuticas que requerem do assistente social pareceres fundamentados nas legislações em vigor na área de Saúde Mental, visando garantir a proteção dos pacientes destes locais e a adequação dos serviços. Geralmente não há assistente social compondo a equipe técnica das Comunidades Terapêuticas.

\footnotetext{
${ }^{21}$ BRASIL, Ministério da Saúde. Portaria 3088 de 23 de dezembro de 2011. Institui a Rede de Atenção Psicossocial para pessoas com sofrimento ou transtorno mental e com necessidades decorrentes do uso de crack, álcool e outras drogas, no âmbito do Sistema Único de saúde (SUS). Disponível em: http:// www.brasilsus.com.br/legislacoes/gm/119156-3088.html Acesso em: 08 out. 2013.

${ }^{22}$ Lei $^{\circ} 10.216$ de 6 de abril de 2001. Dispõe sobre a proteção e os direitos das pessoas portadoras de transtornos mentais e redireciona o modelo assistencial em saúde mental. Disponível em Disponível em: http://www.planalto.gov.br/ccivil_03/leis/leis_2001/110216.htm, acesso 22 maio 2014 Serv. Soc. \& Saúde, Campinas, SP v. 13, n. 2 (18) p. 205-224 jul./dez. 2014 ISSN 1676-6806
} 
Os pareceres técnicos têm sido utilizados, pelos membros do Ministério Público, para propositura de Ações Civis Públicas ${ }^{23}$, instauração de Inquéritos Civis $^{24}$ e celebração de TACs - Termos de Ajuste de Conduta $^{25}$. Quando se avalia a necessidade, indica-se a inspeção de outros órgãos competentes na atuação da área de álcool e outras drogas para complementação de dados técnicos.

\section{- Educação}

$\mathrm{Na}$ área da educação foram enviadas poucas solicitações ao NAT da Regional de Campinas, como avaliações de projetos de adequação da educação inclusiva, municipalização da educação infantil e avaliação do funcionamento da APAE em um município.

\section{ATUAÇÃO NA GARANTIA DE DIREITOS COLETIVOS}

O NAT da regional Campinas tem avaliado planos municipais, composição e funcionamento de conselhos tutelares, participações em reuniões de Conselhos de Direitos que são "espaços de trabalho que os assistentes sociais podem contribuir para o fortalecimento dos sujeitos políticos na perspectiva da garantia e/ou ampliação dos direitos sociais, tendo no horizonte a emancipação humana" (BRAVO, 2009, p. 409).

Recentemente o NAT de Campinas participou da elaboração do Plano Municipal Decenal de Medidas Socioeducativas de Campinas juntamente com os Promotores de Infância e Juventude de Campinas, Secretaria de Cidadania, Assistência e Inclusão Social, Secretaria da Saúde, ONGs executoras de medidas socioeducativas em meio aberto, Fundação CASA, Vara da Infância e Juventude, Defensoria Pública, Universidades, dentre outros serviços, com supervisão técnica externa. Todas as

\footnotetext{
${ }^{23}$ Ação Civil Pública: acionamento judicial promovido pelo Ministério Público ou outros colegitimados com o fim de tutelar interesses transindividuais, tais como: meio ambiente, patrimônio público, consumidor, idoso, infância e juventude. Lei 7.347/85.

${ }^{24}$ Inquérito Civil: Procedimento investigatório a cargo do Ministério Público destinado basicamente a colher elementos de convicção para eventual propositura de ação civil pública ou outras medidas judiciais e extrajudiciais.

${ }^{25}$ TAC - Termo de Ajustamento de Conduta: ato administrativo negocial em que o Ministério Público ou outro órgão público toma de uma pessoa física ou jurídica um compromisso de ajustamento de conduta às exigências legais, sendo dotado de força de título executivo extrajudicial.

Serv. Soc. \& Saúde, Campinas, SP v. 13, n. 2 (18) p. 205-224 jul./dez. 2014 ISSN 1676-6806
} 
instituições envolvidas se debruçaram detidamente na construção do Plano MSE que terá vigência por 10 anos.

O Ministério Público participou assiduamente nas reuniões, expondo problemas e irregularidades que foram constatadas em inspeções e denúncias. Foram compiladas todas as questões que a Promotoria da Infância e Juventude avalia que devem ser incluídas no Plano Municipal de Medidas Socioeducativas para promover a consolidação do plano nos próximos dez anos, avançando para a melhoria da execução das medidas socioeducativas - meio aberto e meio fechado - no município de Campinas. Após seminário de apresentação ao público e abertura para consulta pública durante 60 dias, o Plano MSE de Campinas será finalizado em fevereiro de 2015.

A assessoria técnica do NAT tem sido enfatizada em planos de atuação do Ministério Público, contribuição nas atuações de grupos especiais dentro da instituição, o que tem ensejado a valorização profissional dos técnicos do NAT, estendendo-se gradativamente a atuação dos técnicos no MP/SP.

O NAT em todo o Estado de São Paulo tem participado da Rede Protetiva de Direitos Sociais. Na regional de Campinas o grupo de promotores tem se articulado com a equipe do NAT para discutir e avaliar os principais déficits da rede de saúde mental dos munícipios da área de abrangência. Em interlocução com a Secretaria Estadual da Saúde, com a articuladora da DRS VII e Secretaria Municipal da Saúde de Campinas, estão sendo levantadas as principais defasagens na região e os problemas que demandam atenção imediata devido à criticidade eminente. Estas reuniões já estão resultando em propostas de adequações e implantações de serviços em vários municípios.

\section{CONSIDERAÇÕES FINAIS}

Passados mais de 26 anos da promulgação de nossa Constituição Federal, que delineou modelo de Estado Democrático e Social de Direito, pródigo na exposição de garantias fundamentais formais (individuais e sociais) e na definição de fins sociais desejáveis, conclui-se que segue atual e desafiador o objetivo de dar concretude a tais garantias e fins.

Tendo em vista o caráter apenas coadjuvante que os Poderes do Estado têm dado ao atingimento dos mandamentos constitucionais, conclui-se que a maturidade de nosso Estado Democrático e Social de Direito passa, necessariamente, por um Ministério Serv. Soc. \& Saúde, Campinas, SP v. 13, n. 2 (18) p. 205-224 jul./dez. 2014 ISSN 1676-6806 
Público independente e efetivo, que desenvolva a contento o nobre mister de tutelar os interesses individuais e sociais indisponíveis.

Com tal missão, a experiência prática evidencia a imprescindibilidade do assessoramento técnico de profissionais do Serviço Social, Psicologia, dentre outros. O Núcleo de Assessoramento Técnica Psicossocial tem favorecido o estreitamento da relação e articulação do MP/SP com as organizações governamentais, não governamentais e privadas, propiciando a mudança da concepção de que o Ministério Público é somente agente fiscalizador, mas também é agente de transformação social, beneficiando parcerias que objetivam a qualidade dos serviços e garantia dos direitos sociais. Essa desmistificação da função do MP visa propiciar a consolidação da universalização dos direitos.

A partir da perspectiva técnica do NAT em avaliações de políticas públicas sociais, visitas de inspeções, dentre outras atuações já discutidas, muitos promotores de justiça estão fundamentando Ações Civis Públicas, Inquéritos Civis e TACs (Termos de Ajustamento de Conduta) com apontamentos e sugestões dos pareceres técnicos.

[...] Ao serem diagnosticadas possíveis falhas nos atendimentos das instituições visitadas, as possiblidades de dirimi-las certamente aumentarão. Além do mais, ao conhecer in loco as limitações e vantagens de determinada instituição, o profissional sociojurídico fundamentará melhor seu parecer quanto ao acolhimento ou a internação de uma criança ou de um adolescente (MAGALHÃES, 2003, p. 57).

Nota-se a importância da equipe do NAT no assessoramento ao MP/SP para efetivação da atuação pautada tecnicamente.

Em apenas três anos de atuação, o NAT da Regional de Campinas alcançou resultados positivos, observados nas devolutivas dos promotores de justiça das providências tomadas a partir dos relatórios psicossociais e reuniões. $\mathrm{O}$ crescimento e fortalecimento do NAT no MP/SP demandam incessante busca de aprofundamento de saberes e consciência do inacabamento (FREIRE, 1999), lutando pelo espaço conquistado dentro de uma instituição que é promotora de direitos, espaço privilegiado para atuação do assistente social na garantia dos direitos sociais e da qualidade dos serviços ofertados à população. 


\section{Referências Bibliográficas}

ARRUDA, I. C. de. Serviço social no Ministério Público: consolidação de uma proposta de trabalho na defesa de políticas sociais. In: Serviço Social e temas sociojurídicosdebates e experiências. Rio de Janeiro: 2014, p. 143-158.

BADÍN, A. S. Controle Judicial das Políticas Públicas. São Paulo: Malheiros, 2013.

BARROSO, L. R. O direito constitucional e a efetividade de suas normas. $9^{\text {a }}$ Edição São Paulo: Renovar, 2013.

BRASIL. Constituição da República Federativa do Brasil de 1988. Disponível em: http://www.planalto.gov.br/ccivil_03/constituicao/ConstituicaoCompilado.htm Acesso 29 nov. 2014.

BRASIL. Lei Federal n. 8.069, de 13 de julho de 1990. Dispõe sobre o Estatuto da Criança e do Adolescente e dá outras providências. Disponível em:

http://www.planalto.gov.br/ccivil_03/leis/18069.htm Acesso 29 nov. 2014.

BRASIL. Ministério do Desenvolvimento Social e Combate à Fome. Secretaria Nacional de Assistência Social. Norma Operacional Básica de Recursos Humanos do SUAS. Brasília, DF. 2006. 45 p.

BRASIL. Ministério do desenvolvimento social e combate à fome. Secretaria Nacional de Assistência Social. Política Nacional de Assistência Social. Brasília, DF. 2004. 67 p.

BRASIL. Resolução $n^{0}$ 109, de 11 de novembro de 2009. Aprova a Tipificação Nacional dos Serviços Socioassistenciais. Diário Oficial da União, Brasília, DF, 22 jan. 2013.

BOSQUETTI, I. Avaliação de políticas, programas e projetos sociais. In: CFESS/ABEPSS (Orgs.). Serviço Social: direitos sociais e competências profissionais. Brasília: CEFESS/ABEPSS, 2009, p. 575-591.

BRAVO, M. I. O trabalho do assistente social nas instâncias públicas de controle democrático. In: CFESS/ABEPSS (Orgs.). Serviço Social: direitos sociais e competências profissionais. Brasília: CEFESS/ABEPSS, 2009, p. 393-410.

CANELA JÚNIOR, O. Controle Judicial de Políticas Públicas, São Paulo: Saraiva, 2011.

COMPARATO, F. K. A afirmação histórica dos Direitos Humanos. VII edição São Paulo: Saraiva, 2010. 
CONSELHO NACIONAL DE ASSISTÊNCIA SOCIAL. Resolução $\mathbf{n}^{\mathbf{0}} \mathbf{1 7}$, de 20 de junho de 2011.Ratifica a equipe de referência definida pela Norma Operacional Básica de Recursos Humanos do Sistema Único de Assistência Social - NOB-RH/SUAS e reconhece as categorias profissionais de nível superior para atender as especificidades dos serviços socioassistenciais e das funções essenciais de gestão do Sistema Único de Assistência Social - SUAS. Diário Oficial da União, Brasília, DF, 22 jan. 2014.

CONSELHO NACIONAL DE ASSISTÊNCIA SOCIAL. Resolução $\mathbf{n}^{\mathbf{0}}$ 33, de 12 de Dezembro de 2012. Aprova a Norma Operacional Básica do Sistema Único de Assistência Social-NOB/SUAS.

Disponível em: http://www.mds.gov.br/cnas/noticias/publicada-hoje-a-nova-normaoperacional-basica-nob-suas-2012. Acesso 18 de nov. 2014.

FREIRE, P. Pedagogia da Autonomia: Saberes Necessários a Prática Educativa. 11. Ed. São Paulo: PAZ E TERRA, 1999.

IAMAMOTO, M. V. O Serviço Social na cena contemporânea. In: CFESS/ABEPSS (Orgs.). Serviço Social: direitos sociais e competências profissionais. Brasília: CEFESS/ABEPSS, 2009, p. 15-50.

LIBERATTI, W. D. Políticas Públicas no Estado Constitucional. São Paulo: Atlas, 2013.

MAGALHÃES, S. M. Avaliação e Linguagem - relatórios, laudos e pareceres. São Paulo: Veras Editora, 2003.

MANCUSO, R. de C. Acesso à justiça: condicionantes legítimas e ilegítimas. São Paulo: Revista dos Tribunais. 2011. p. 80.

MONTESQUIEU, Barão de. Do Espírito das Leis. São Paulo: Editora Martins Fontes, 2000.

RAICHELIS, R. O trabalho do assistente social na esfera estatal. In: CFESS/ABEPSS (Orgs.). Serviço Social: direitos sociais e competências profissionais. Brasília: CEFESS/ABEPSS, 2009, p. 377-392.

ROSA, L. C. dos S.; MELO, T. M. F. S. Inserções do Assistente Social em Saúde Mental: em foco o trabalho com as famílias. Serviço Social \& Saúde. UNICAMPCampinas, v. VII-VIII, n. 7-8, Campinas: Cortez, 2009, p. 75-105. 